\title{
Correction to: Temporal and spatial evolution trends of drought in northern Shaanxi of China: 1960-2100
}

\author{
Xiaoyun Wang ${ }^{1,2} \cdot$ La Zhuo $^{2,3} \cdot{\text { Chong } \mathrm{Li}^{1,2} \cdot \text { Bernard A Engel }^{4} \cdot \text { Shikun Sun }}^{1,2,5} \cdot$ Yubao Wang ${ }^{1,2,4,5}$
}

Published online: 18 December 2019

(C) Springer-Verlag GmbH Austria, part of Springer Nature 2019

\section{Correction to: Theoretical and Applied Climatology https://doi.org/10.1007/s00704-019-03024-2}

The original version of this article unfortunately contained a mistake. The presentation of Fig. 3 was incorrect. The ordinates of Fig. $3 \mathrm{~b}$ and Fig. $3 \mathrm{c}$ should be 12-SPEI and 12-SPI.
The descriptions below the picture should also be 12-SPEI and 12-SPI (3-SPEI and 3-SPI should be deleted). The corrected figure is given below.

The original article has been corrected.

The online version of the original article can be found at https://doi.org/ 10.1007/s00704-019-03024-2

Yubao Wang

yubaowang75@gmail.com

1 Key Laboratory for Agricultural Soil and Water Engineering in Arid Area of Ministry of Education, Northwest A\&F University,

Yangling 712100, Shaanxi, People's Republic of China

2 Institute of Water Saving Agriculture in Arid regions of China, Northwest A\&F University, Yangling 712100, Shaanxi, People's Republic of China

3 Institute of Soil and Water Conservation of Northwest A\&F University, Yangling 712100, Shaanxi, People's Republic of China

4 Department of Agricultural and Biological Engineering, Purdue University, West Lafayette, IN 47906, USA

5 College of Water Resources and Architectural Engineering, Northwest A\&F University, Yangling 712100, People's Republic of China 

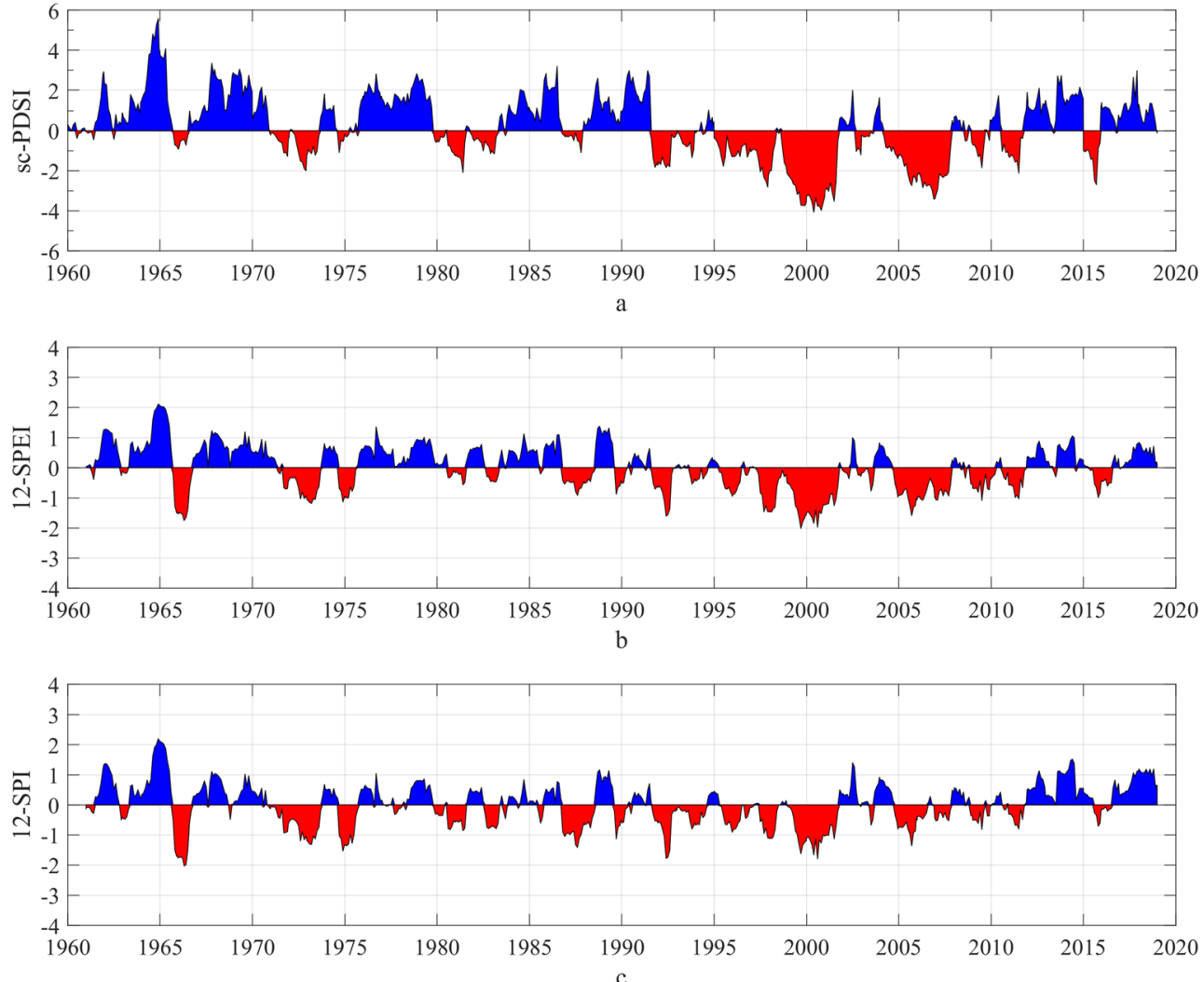

Fig. 3 Values for three drought indices in northern Shaanxi (1960 2018). a sc-PDSI. b 12-SPEI. c 12-SPI

Publisher's note Springer Nature remains neutral with regard to jurisdictional claims in published maps and institutional affiliations. 